\title{
Gene Flow Among Three Races of European Corn Borers (Lepidoptera: Pyralidae) in New York State
}

\author{
THOMAS J. GLOVER,' JANET J. KNODEL, ${ }^{2}$ PAUL S. ROBBINS,' \\ CHARLES J. ECKENRODE, ${ }^{\prime}$ AND WENDELL L. ROELOFS ${ }^{i}$ \\ New York State Agricultural Experiment Station, \\ Cornell University, Geneva, New York 14456
}

\begin{abstract}
Environ. Entomol. 20(5): 1356-1362 (1991)
ABSTRACT In New York state, there are three races of European corn borer moths, which are characterized principally by differences in voltinism and the sex pheromone communication system. One race is bivoltine, with females producing and males responding to a 99:1 $E / Z$ isomeric ratio of $\Delta 11-14:$ OAc's as the sex pheromone. Two races, one univoltine and one bivoltine, produce and respond to a 3:97 E/Z blend of $\triangle 11-14: O A c$ 's. The races are referred to as $\mathrm{BE}, \mathrm{UZ}$, and $\mathrm{BZ}$ to denote these differences. Analyses by gas chromatography of field-collected females indicate that there is significant hybridization between the $\mathrm{Z}$ and $E$ races when in sympatry, with hybrid females producing a 68:32 ratio of $E / Z 11-14$ : OAc. Gene flow among the races was investigated using differences in triose phosphate isomerase (TPI) allozyme frequencies of moths from sites sampled across the state. The fixed nature of the $T p i-1$ allele in the $\mathrm{BE}$ race and increases in the $T p i-1$ allele frequencies in UZ populations in sympatry with the $\mathrm{BE}$ race support the hypothesis that gene flow following hybridization is unidirectional from $\mathrm{BE}$ populations into the $\mathrm{Z}$ populations. In addition, the TPI genotypes of the 10 hybrid females analyzed were consistent with hybridization occurring by $\mathrm{E}$ males mating with $\mathrm{Z}$ females.
\end{abstract}

KEY WORDS Insecta, Ostrinia nubilalis, gene flow, hybridization

IN NEW YORK STATE, the European corn borer, Ostrinia nubilalis (Hübner) (Pyralidae), exists as a constellation of three races which are morphologically indistinguishable but have distinct differences in voltinism, host plant range, and sex pheromone communication systems. Some of these differences most likely existed among European populations of this pest when they were introduced into North America with shipments of broom corn from central Europe and Italy between 1909 and 1914 (Smith 1920). The first positive identification of this species in the United States was made by Vinal (1917), and it has been extensively studied since that time. For a review of the early studies on life histories and the distribution of voltinism biotypes, see Brindley \& Dicke (1963). Most recently, the voltinism patterns of European corn borer in New York have been determined using blacklight traps (Eckenrode et al. 1983) and direct field collection of larvae and pupae (Roelofs et al. 1985). From these studies, it was clear that both bivoltine and univoltine populations exist in New York, often sympatrically.

Klun (1968) isolated and identified the primary component of the European corn borer sex pheromone as (Z)-11-tetradecenyl acetate (Z11-14: OAc) and found that this compound was attractive to males in the field in Iowa (Klun \& Robinson 1971). Subsequently, an isomeric mixture (96\% Z11-14:

\footnotetext{
' Department of Entomology.

${ }^{2}$ IPM Support Group.
}

OAc, 4\% (E)-11-tetradecenyl acetate (E11-14: OAc)) was shown to be optimum for trapping males in Iowa (Klun et al. 1973). Pheromone polymorphism became evident when the opposite blend (4: $96 \mathrm{Z} / \mathrm{E}$ ) was discovered in some New York populations (Kochansky et al. 1975). Cardé et al. (1978) suggested that the two types based on pheromone blend differences might coexist in certain areas but were not freely interbreeding and might actually have evolved to the status of semi- or sibling species. Laboratory hybridization between the two types was obtained (Liebherr \& Roelofs 1975), and Klun \& Maini (1979) found that hybrid females produce pheromone blends with approximately a $35: 65 \mathrm{Z} / \mathrm{E}$ ratio. They also reported that the isomeric composition of the pheromone secretions is controlled by a simple Mendelian factor with the two alleles exhibiting incomplete dominance in the hybrids.

More recently, in New York, pheromone analyses by gas chromatography of individual females reared from field-collected larvae and pupae associated with bivoltine flights in June and August and a univoltine flight in July confirmed the existence of a bivoltine type producing a pheromone blend using $\approx 99 \%$ E11-14:OAc (designated BE), a second bivoltine type (designated $\mathrm{BZ}$ ) using $\mathrm{Zll}$ 14: OAc as its primary pheromone component, and a univoltine type using mostly Z11-14: OAc (designated UZ) (Roelofs et al. 1985). To date, no univoltine $\mathrm{E}$ populations have been detected. Data from limited light trap records and pheromone 
gland analyses showed that the $\mathrm{BZ}$ and $\mathrm{BE}$ populations are allopatric, whereas the UZ type appeared to be isolated in some regions but in sympatry with the bivoltine populations in other regions (Roelofs et al. 1985).

Pure cultures of the three races were established in our laboratories. Using these cultures, we elucidated distinct genetic factors controlling the female sex pheromone ratio (autosomal), male antennal electrophysiological response at the sensillum level (autosomal), and male behavioral response in flight tunnel assays (sex-linked) (Roelofs et al. 1987). Each of the factors is fixed in the $E$ or $Z$ pheromone types and is inherited independently of the other two (Löfstedt et al. 1989).

Other differences among the three New York races in culture have been identified, including subtle differences in pheromone blend discrimination by BZ and UZ males (Glover et al. 1987) and differences in upwind flight response profiles to sex pheromone behavioral antagonists (Glover et al. 1989). Differences in host plant survivorship (Straub et al. 1986, Webb et al. 1987, Eckenrode \& Webb 1989) and susceptibility to insecticides by different populations (Kuhr \& Davis 1975) have also been documented.

From these studies, it is clear that these three races have life history differences that are of considerable importance for effective monitoring and control programs, and that there are genetic bases for these differences. While differences in voltinism and in sex pheromone communication systems place obvious restrictions on gene flow among the races, some interracial hybridization in the field has been documented (Roelofs et al. 1985), although the extent of genetic interaction among these races has not been extensively studied.

European corn borer populations have been surveyed several times for allozyme differences. Harrison \& Vawter (1977) investigated 10 loci in sympatric populations of $Z$ type and $E$ type from Amity Hall, Pa., as well as $E$ type from Geneva, N.Y. They found statistically significant allele frequency differences at four loci in the sympatric populations but concluded that the so-called strains exhibited remarkable genetic similarity. In 1980, Cianchi et al. measured the genetic distance between the two pheromone strains of European corn borer $(E$ from New York, $Z$ from Iowa) using a sample of 30 geneenzyme systems, with 14 of the loci coding for variable-substrate and regulatory enzymes and 16 of the loci coding for nonregulatory enzymes. Using Nei's measure of standard genetic distance and calculating the distances separately for regulatory and nonregulatory enzymes, they found genetic differences between the strains comparable with those for subspecies or sibling species in Peromyscus and Aedes.

In 1984, we commissioned an allozyme screen of the three New York European corn borer races under culture via standard horizontal starch gel electrophoresis (performed by the Cornell Labo- ratory for Ecological and Evolutionary Genetics, Department of Natural Resources, College of Agriculture and Life Sciences, Cornell University, under the direction of Bernie May). Twenty randomly chosen females and 20 randomly chosen males from each culture were screened for 34 enzymes. Of the enzymes tested, 21 appeared to be monomorphic and of the remaining enzymes, only the sex-linked locus coding for triose phosphate isomerase (TPI), showed clear differences among cultures. This locus was fixed for the Tpi-1 allele in the $\mathrm{BE}$ colony, had intermediate frequencies of Tpi-1 and Tpi-2 in the BZ colony, and was $97 \%$ $T p i-2$ in the UZ colony. Subsequently, in several samples of field-collected BE, we found only Tpi-1 genotypes, whereas the samples from both $\mathrm{BZ}$ and UZ field collections always yielded intermediate frequencies for the two alleles (T.J.G., unpublished data). In addition, a recent sample of bivoltine $\mathrm{Z}$ borers from Iowa yielded allele frequencies of 0.603 for Tpi-1 and 0.397 for Tpi-2. Interestingly, Cianchi et al. (1980) found the BE population $(n=31)$ from New York and a $Z$ population $(n=10)$ from Iowa to both be monomorphic for TPI.

Because the BE populations seemed to lack variability at the TPI locus, we felt that allele frequencies of this gene could be used to gauge the amount of gene flow that occurs among the three races in the New York European corn borer complex. TPI genotypes were determined for samples collected from 16 field sites, which were also being studied for population composition using pheromone traps.

\section{Materials and Methods}

Survey Sites. During 1988 and 1989, 14 sites $\approx 32 \mathrm{~km}$ apart along an east-west line from Albany, N.Y., to Buffalo, N.Y., were sampled (Fig. 1). The sites had been planted with field corn that was harvested for either grain or silage in the fall before the survey. All sites were located along U.S. route 20 with the exception of the Eden site, which was on U.S. route 62 . The sites and their nearest towncity include the following (proceeding eastward): 1, Eden; 2, Alden; 3, Bethany; 4, Avon; 5, Canandaigua; 6, Geneva; 7, Cayuga; 8, Skaneateles; 9 , Pompey Center; 10, Bouckville; 11 , West Winfield; 12, East Springfield; 13, Carlisle; and 14, Duanesberg. Approximately 50-100 overwintering larvae were collected from the corn stubble at each site between 25 April and 4 May in 1988 and between 12 April and 9 May in 1989.

In 1989, four additional sites (Avon, Hamlin, Hilton, and West Henrietta) were surveyed on 4 May. Field corn was sampled at Avon, Hilton, and West Henrietta and processing sweet corn at Hamlin. The Avon site was close to site 4 and data have been combined for these two sites. The West Henrietta site was $\approx 16 \mathrm{~km}$ north of site 4 and is henceforth referred to as site 15 . The Hamlin and Hilton sites were $8 \mathrm{~km}$ apart approximately $32 \mathrm{~km}$ north- 


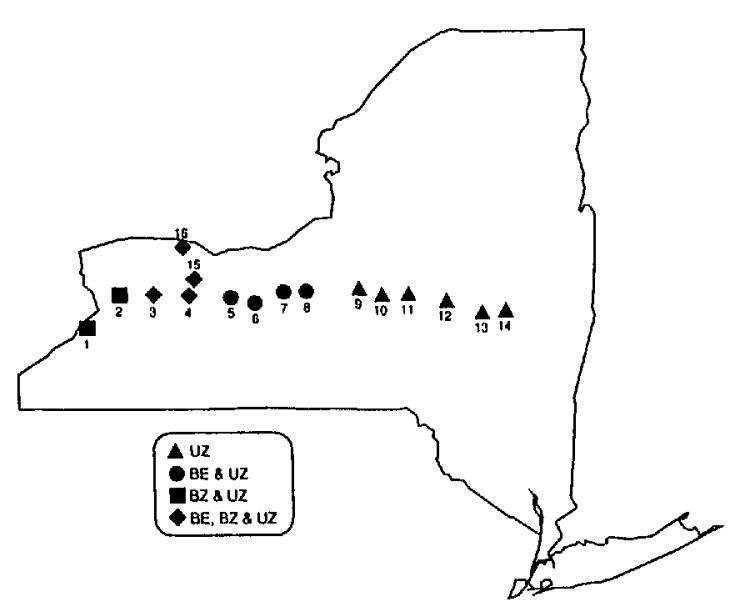

Fig. 1. Survey sites for races of European corn borer in New York.

west of site 15. Data from these sites were combined; the sites are referred to as site 16 .

In addition to the field-collected overwintering larvae, pheromone traps were monitored for the different races of the European corn borer at each field site. This was part of a trap survey to determine the distribution of the races in New York state. Wire cone traps were used in 1988 (sites 114) and the Scentry Heliothis net traps in 1989 (sites 4, 15, and 16).

Voltinism Determination. The overwintering larvae collected form the sites described above were placed individually in $35.5-\mathrm{ml}$ plastic creamers with a moistened section of dental wick and held at $30^{\circ} \mathrm{C}$ on a 16:8 (L:D) photoperiod. The larvae were checked every $48 \mathrm{~h}$, and a record was kept of the date of pupation. Under these conditions, bivoltine larvae pupate within $14 \mathrm{~d}$ and univoltine larvae pupate in $>20 \mathrm{~d}$. A series of unpublished experiments by P.S.R. and C.J.E. indicated that the time to pupation can be used to determine unequivocally the voltinism of field-collected larvae. After eclosion, the sex pheromone glands of the female moths were analyzed via gas chromatography to determine their individual sex pheromone composition following the procedures outlined by Roelofs et al. (1985).

TPI Phenotype Determination. Both male and female adult moths were stored individually at $-70^{\circ} \mathrm{C}$ until they were analyzed via electrophoresis for TPI phenotype. The samples were run on Titan III cellulose acetate plates and stained using the procedures described by Glover et al. (1990). In the European corn borer populations examined to date, there are principally two allozymes. The form that moves more rapidly to the anode, designated here $T p i-1$, and a slower form, designated $T p i-2$. A rare $(<1$ in 500) form faster than the $T p i-1$ form and an equally rare form slower than the $T p i-2$ form have been noted in some very large samples of field-collected moths, but because of their rarity we disregard them in the present discussion.
Because TPI is a randomly associating dimeric enzyme controlled by a sex-linked gene, it exhibits a three-band pattern only in heterozygous males. Homozygous males and hemizygous females exhibit a single band at either the $T p i-1$ position or the $T p i-2$ position (Glover et al. 1990).

In addition to the adults raised from field-collected overwintering larvae, some insects were analyzed that had been trapped at the four additional sites in 1989 with Scentry Heliothis net traps baited with $100 \mu \mathrm{g}$ two-component pheromone lures. These insects were taken from traps baited with the $Z$ pheromone blend and were caught on the peak days of the univoltine flights. The insects were removed weekly from the traps and were stored at $-70^{\circ} \mathrm{C}$ until they were analyzed by electrophoresis for TPI genotype. Although the banding pattern was not as distinct as with material that had been frozen alive, the TPI allozyme patterns were still discernible, and these data were used to increase the sample sizes for the UZ populations at these sites $(4,15,16)$.

\section{Results}

In Fig. 1, the distribution of the three races is illustrated along the $480 \mathrm{~km}$ east-west transect. The easternmost sites (9-14) have exclusively UZ populations. The sites from 5 to 8 exhibit a mixture of $\mathrm{UZ}$ populations and BE populations. Sites $3,4,15$, and 16 have $\mathrm{UZ}$ populations and both bivoltine populations; the $\mathrm{BE}$ is present in higher densities than the BZ at all sites except site 3 . The westernmost sites ( 1 and 2) had only UZ and BZ populations. The relative densities for the populations at various sites were determined by the total trap catch per season from the pheromone trap survey.

The voltinism as determined by postdiapause development times for samples collected as overwintering larvae are summarized in Table 1. Data from 1988 and 1989 were similar and have been combined. Sample sizes differ because of varying mortality due to several causes, including parasitism. Also, some sites, such as 15 and 16 , represent collection over only 1 yr and some sites, such as 4 and 16 , have combined data sets from two nearby collection sites. The numbers, therefore, do not reflect actual field abundance of the various populations among these sites. Of the 1,356 insects whose voltinism could be determined, 652 were females. To determine pheromone phenotype, analysis by gas chromatography was attempted on 397 of these females; 102 analyses were inconclusive because of mortality before gland extraction or very low pheromone titer. The 295 successful analyses are summarized in Table 1 in parentheses next to the total number of females of each voltinism type at each site. Of the 150 females analyzed from sites where $\mathrm{Z}$ and $\mathrm{E}$ populations were sympatric, thirteen (8.7\%) were found to be hybrids with 12 of these bivoltine (11.4\%,n=105) and 1 univoltine $(2.2 \%, n=45)$. Because random samples were not analyzed at each 
Table 1. Voltinism of field-collected overwintering larvae of European corn borer as determined by postdiapause development times ${ }^{a}$

\begin{tabular}{|c|c|c|c|c|}
\hline \multirow{2}{*}{ Site } & \multicolumn{2}{|r|}{ Bivoltine } & \multicolumn{2}{|c|}{ Univoltine } \\
\hline & $\$ d$ & 98 & đơ & \$q \\
\hline 1 & 66 & $34(23 Z)$ & 12 & $17(7 Z)$ \\
\hline 2 & 11 & $8(7 Z)$ & 24 & $34(16 Z)$ \\
\hline 3 & 3 & 2 & 38 & $33(8 Z)$ \\
\hline 4 & 55 & $57(36 E, 7 Z, 5 H)$ & 26 & $29(4 Z)$ \\
\hline 5 & 6 & $4(3 E, 1 H)$ & 44 & $33(15 Z)$ \\
\hline 6 & 19 & $11\langle 3 E\rangle$ & 39 & $65(1 H)$ \\
\hline 7 & 14 & $9(3 E, 1 Z, 2 H)$ & 34 & $20(7 Z)$ \\
\hline 8 & 1 & $2(2 E)$ & 43 & $31(10 Z)$ \\
\hline 9 & - & - & 35 & $26(13 Z)$ \\
\hline 10 & - & - & 37 & $31(10 Z)$ \\
\hline 11 & 1 & - & 29 & $36(17 Z)$ \\
\hline 12 & - & - & 40 & $34(15 Z)$ \\
\hline 13 & - & - & 31 & $45(17 Z)$ \\
\hline 14 & - & - & 34 & $35(20 Z)$ \\
\hline 15 & 12 & $12(8 E, 2 H)$ & 7 & 2 \\
\hline 16 & 32 & $35(30 E, 2 H)$ & 11 & 7 \\
\hline
\end{tabular}

a Values in parentheses are pheromone types of females as determined by gas chromatography. $E$, pheromone blend typical of $E$ race; $Z$, pheromone blend typical of $Z$ races; $H$, pheromone blend typical of $Z \times E F_{1}$ females. site for each population, these numbers indicate only that considerable interracial hybridization occurs in areas of sympatry.

In Table 2, the TPI genotypic arrays for both males and females are listed for each population at each site. Not all insects in Table 1 were analyzed for TPI genotype. Again, the numbers of insects analyzed do not reflect relative abundance of the various populations. At sites $3,4,15$, and 16 , some insects were classified as bivoltine but were not further partitioned into BE or BZ and, therefore, are listed simply as B's. All analyzed insects were collected as overwintering larvae except for a portion of the UZ males at sites 4 (57), 15 (27), and $16(88)$. These additional UZ males were caught in 1989 with Scentry Heliothis net pheromone traps baited with $100 \mu \mathrm{g}$ of $\mathrm{Z}$ pheromone mixtures on rubber septa.

From Tables 1 and 2, it is evident that the eastern sites (9-14) exhibit only UZ populations. With respect to the TPI locus, all these sites are in approximate Hardy-Weinberg equilibrium for a sexlinked gene with frequencies of the Tpi-1 allele ranging from 0.34 to 0.17 and with an overall fre-

Table 2. Distribution of races, TPI phenotypes, and allele frequencies for 16 siles across upstate New York

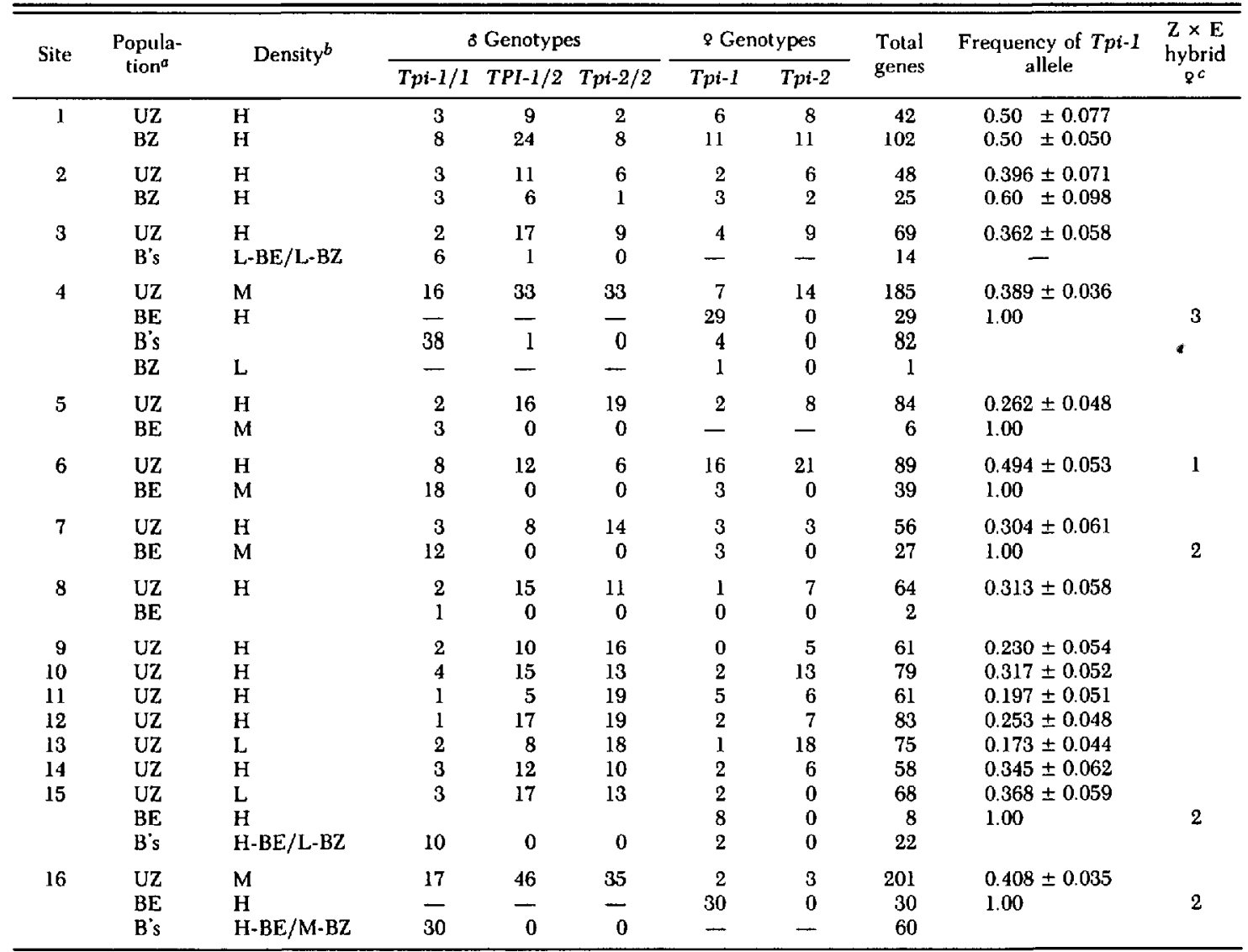

${ }^{a} \mathrm{UZ}$, univoltine with $\mathrm{Z}$ pheromone; $\mathrm{BZ}$, bivoltine with $\mathrm{Z}$ pheromone; $\mathrm{BE}$. bivoltine with $E$ pheromone; B's, bivoltine without pheromone determination.

${ }^{b}$ Population densities as determined by pheromone trap surveys: $H$, high; $M$, moderate; $L$, low.

${ }^{c}$ All $\mathrm{Z} \times \mathrm{E}$ hybrid females had $T p i-1$ genotype and are in a row denoting appropriate voltinism. 
quency of 0.25 . The $\chi^{2}$ test for homogeneity of gene frequencies $\left(\chi^{2}=8.01, v=5, P>0.1\right.$ ) (Snedecor \& Cochran 1969) indicates that the allele frequencies among these sites are not significantly different. UZ populations at sites 4-7 and 15-16 were in contact with moderate to high populations of BE borers, with analyses by gas chromatography of females yielding at least one $\mathrm{Z} \times \mathrm{E}$ hybrid at each site. In these sites, the $T p i-1$ allele frequency for UZ populations ranged from 0.26 to 0.49 with a mean of 0.38 . The $\chi^{2}$ test for homogeneity of gene frequencies $\left(\chi^{2}=12.02, v=5, P<0.05\right)$ indicates that significant variability among allele frequencies exists in these UZ populations. Each population was, however, in Hardy-Weinberg equilibrium.

Most interestingly, the BE populations at all these sites were fixed for the Tpi-1 allele. Also, the B category for site 4 has 38 homozygous $T p i-1$ males and 1 heterozygote as well as $4 T p i-1$ females (Table 2). Additionally, the $\mathrm{Bs}$ in site 3 have six homozygous Tpi-1 males and one heterozygote. Both of these sites had low populations of $\mathrm{BZ}$ insects in sympatry with the other populations. We feel that the two TPI heterozygotes probably represent $\mathrm{BZ}$ borers and the majority of the insects in the $B$ category for these sites are BE borers. The B at the two northern sites were all Tpi- 1 homozygous males or Tpi-1 hemizygous females. Because the BZ populations were low at these sites relative to the $\mathrm{BE}$ populations, we feel that the majority of the B insects at these sites also were $\mathrm{BE}$ insects.

Finally, the westernmost sites (1 and 2) had high populations of both UZ and BZ borers, but no BE populations. The frequency of the Tpi-1 allele in the $\mathrm{UZ}$ populations averaged 0.44 at these sites and the frequency of the Tpi-l allele in the BZ populations averaged 0.52 . These frequencies were not signiffcantly different according to the $\chi^{2}$ test for differences in two gene frequencies $\left(\chi^{2}=1.20, v\right.$ $=1, P>0.1)(\mathrm{Li} 1976)$. Once again, both populations at both sites demonstrated a Hardy-Weinberg distribution of genotypes for the TPI locus.

Comparing the UZ populations overall allele frequency for sites 9 through 14 that have only UZ borers to sites 4 through 7,15 , and 16 that have high BE populations in sympatry with UZ populations, the allele frequencies were 0.252 versus 0.384 . According to the $\chi^{2}$ test for differences in gene frequencies $\left(\chi^{2}=21.8, v=1, P<0.005\right)$, the frequency of $T p i-1$ is significantly lower in the isolated $\mathrm{UZ}$ populations. Of the $13 \mathrm{Z} \times \mathrm{E}$ hybrid females found via gas chromatography (Table 1), 10 were analyzed for TPI genotype (Table 2). All of these hybrid females exhibited the Tpi-1 genotype.

\section{Discussion}

There are several interesting features of the data presented in Table 2. First, the BE population appears to be fixed for the $T p i-1$ allele, even in areas where it is sympatric and hybridizes with the $\mathrm{Z}$ races. The best evidence for this is that all the $\mathrm{BE}$ females $(n=73)$ analyzed for pheromone type by gas chromatography had the same TPI genotype (Tpi-1), 34 males determined to be BE by virtue of their voltinism and the absence of $\mathrm{BZ}$ at their sites were found to be homozygotes for $T p i-1$. In addition, our original BE colony screened in 1984 and begun from field-collected insects in Geneva was fixed for the $T p i-1$ allele $(n=60)$, and Cianchi et al. (1980) found the E strain from Geneva to be monomorphic with respect to this enzyme ( $n=$ 31). To date, every insect conclusively shown to be bivoltine $\mathrm{E}$ has exhibited the $T p i$ - 1 genotype. These insects include further samples from our BE colonies and a small sample $(n=8)$ from a North Carolina E colony (T.J.G., unpublished data).

Second, it is clear that there is considerable hybridization between the $\mathrm{Z}$ and $\mathrm{E}$ populations as is evidenced by the 13 hybrid females found by gas chromatography (Table 1). Some of these must be $\mathrm{UZ} \times \mathrm{BE}$ hybrids because they were generated at sites devoid of BZ borers. Initially, this seems improbable given the temporal differences in emergence of the bivoltine and univoltine insects, but blacklight (Eckenrode et al. 1983) and pheromone trap surveys indicate that there is considerable overlap of the univoltine flight and the second light of the bivoltine insects.

Third, UZ and BZ populations at all sites approximate Hardy-Weinberg genotype distributions for the Tpi-1 and Tpi-2 allozymes, indicating that there is probably little or no selection pressure on this allozyme polymorphism.

Lastly, the frequency of $T p i-1$ in the UZ populations is significantly higher in populations that occur in sympatry with $\mathrm{BE}$ or $\mathrm{BZ}$ populations (or both) than in populations that are isolated. It should be noted that the one possible exception to this statement is site 14, which is isolated and has a high frequency of $T p i-1$, but this site is only a few miles from known BE populations in the nearby Mohawk Valley (P.S.R. \& C.J.E., unpublished data).

Taken in their entirety, the TPI allele frequency data form strong circumstantial evidence for a unidirectional gene flow from the $\mathrm{BE}$ race into the various $\mathrm{Z}$ populations. The $\mathrm{BE}$ populations, as far as have been determined, are monomorphic for $T p i-1$. With significant gene flow from the $Z$ populations into the BE population, one would expect to find numbers of Tpi-2 alleles in the BE populations in sympatry with $\mathrm{Z}$ populations. There is a significant increase in $T p i-I$ frequency in the UZ populations in sympatry with BE populations, indicating that migration of genes from $\mathrm{BE}$ to $\mathrm{UZ}$ is increasing this allele frequency. In sites with both $\mathrm{UZ}$ and $\mathrm{BZ}$ populations but not $\mathrm{BE}$ populations, the $T p i-1$ frequencies of the two races are similar. In fact, they are not significantly different from that of a recently analyzed $Z$ culture from Iowa (frequency of $T p i-1,0.603, n=135$ ).

Unidirectional gene flow is indicated by the characteristics of the TPI locus in the populations 
a.
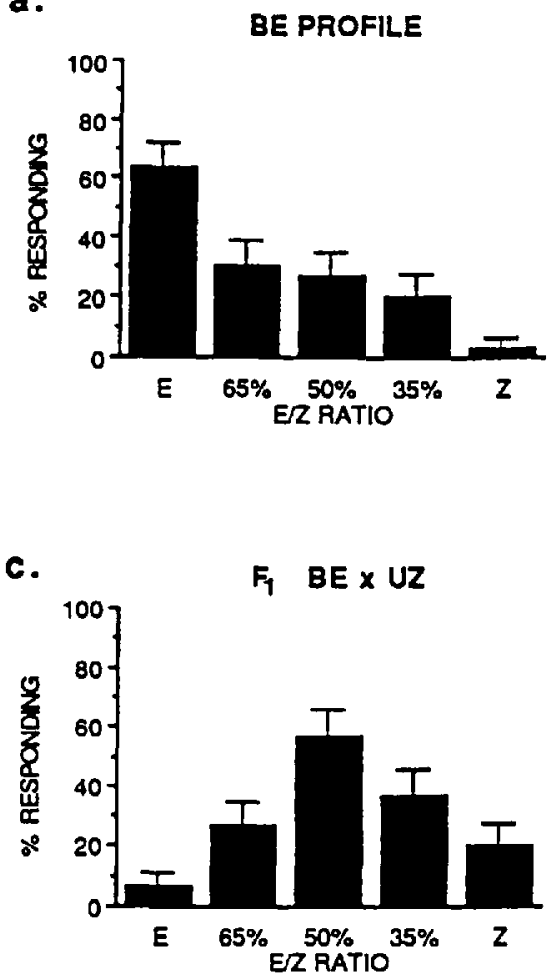

b.

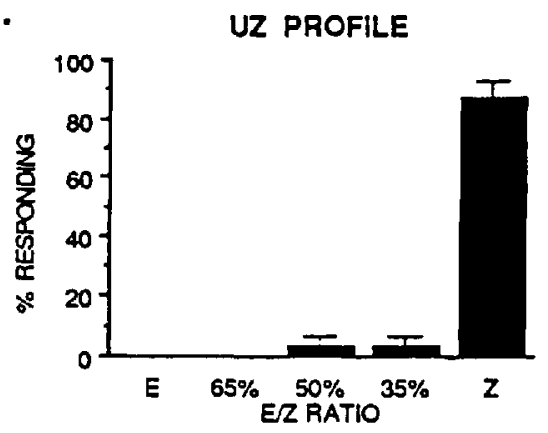

d.

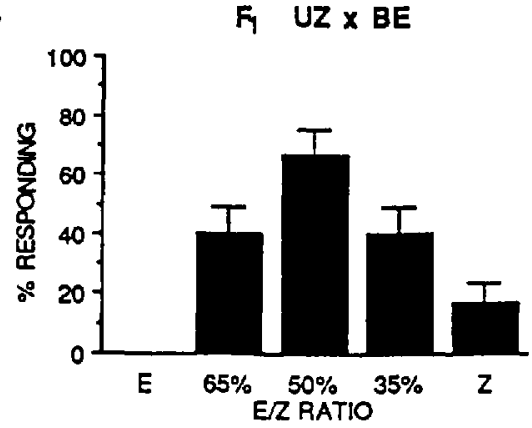

Fig. 2. Behavioral response profiles for $B E, U Z$, and reciprocal $F_{1}$ males in flight tunnel assays. Pheromone blends: $E, 99: 1 ; Z, 3: 97$ E/Z 11-14:OAc. Percentage responding is percentage of individuals tested that completed the behavioral sequence by touching the pheromone lure or displaying or both. Standard deviations of percentages are presented as error bars. Colony profiles and $F_{1}$ profiles were generated by testing 30 insects per blend. (From Glover et al. 1990.)

and sites and also from evidence from flight tunnel data. Studies (Roelofs et al. 1987, Glover et al. 1990) of $\mathrm{E}$ and $\mathrm{Z}$ males tested with the $\mathrm{Z}$ pheromone, the $E$ pheromone, and three intermediate ratios (35: $65,50: 50$, and $65: 35 E$ to $Z 11-14:$ OAc) in a flight tunnel described by Glover et al. (1987), indicate that $\mathbf{E}$ borers are much more likely to respond fully to off-blends than are $\mathrm{Z}$ borers. Fig. 2, taken from Glover et al. (1990), shows that UZ males are highly canalized in their behavioral response. When 30 naive males were flown to each blend, only two insects (one at $50 \%$ and one at $65 \%$ ) responded fully to blends other than the natural $\mathrm{Z}$ blend. BE males, on the other hand, demonstrated a considerably broader response range with $20-30 \%$ of the insects tested responding to intermediate blend ratios and one insect responding to the $Z$ pheromone blend. If these flight tunnel preferences are mirrored in the field, one would expect the interracial matings that occur to be $\mathrm{Z}$ females with $\mathrm{E}$ males. Given this mating, one would expect the hybrid females produced to express the TPI phenotypes of their fathers because the TPI locus is sex-linked (Z-linked) and female moths (ZW) must receive the $\mathrm{Z}$ chromosome from their fathers. Of the 13 female hybrids discovered via gas chromatographc analysis, 10 were further analyzed for TPI phe- notype, and all 10 had the Tpi-I phenotype as expected if their fathers were $\mathrm{BE}$ males.

Roelofs et al. (1987) and Glover et al. (1990) also investigated the response profiles of $F_{1}$ males and demonstrated that hybrid males respond to a wide-range of pheromone blends with significant numbers responding to all blends except the $\mathrm{E}$ pheromone. In fact, in the more recent study (see Fig. 2), only 2 of $30 \mathrm{BE}$ females $\times \mathrm{UZ}$ males $\mathrm{F}_{1}$ males responded to the $E$ blend and none of the $30 \mathrm{UZ}$ females $\times \mathrm{BE}$ males $F_{1}$ males responded to the $E$ blend. Hybrid females would produce $\approx 68$ : $32 \mathrm{E} / \mathrm{Z}$ pheromone blends and would be moderately attractive only to hybrid males or $E$ males. The hybrid males, on the other hand, would respond to rare hybrid females and the more common $\mathrm{Z}$ females. These hybrid males would, therefore, most likely act as the vehicle to transfer genes from the $B E$ population to the $\mathrm{Z}$ populations.

The unidirectional gene flow from BE populations into UZ populations, indicated by the TPI frequency data and supported by the flight tunnel studies, and the apparent ease of gene flow among the $\mathrm{Z}$ populations would generate significant variability in both the $\mathrm{UZ}$ and $\mathrm{BZ}$ races, severely restricting the $B E$ race. The apparent genetic isolation of the $\mathrm{BE}$ race could help explain its more 
limited geographical range. $Z$ races predominate over most of the ECB range in Europe and North America, whereas the $\mathrm{E}$ race is found only at select locations in Switzerland, Italy, and eastern North America. (Klun and cooperators 1975, McLeod et al. 1979, Buechi et al. 1982, Anglade et al. 1984).

\section{Acknowledgment}

We thank M. Campbell, R. Charlton, M. Hessney, S. Hilchey, R. Jurenka, K. Nelson, G. Rule, D. Webb, and K. Wentworth for help in collecting overwintering larvae, and J. Nyrop for statistical advice.

\section{References Cited}

Anglade, P., J. Stockel \& I. W.G.O. Cooperators. 1984. Intraspecific sex-pheromone variability in the European corn borer, Ostrinia nubrialis Hbn. (Lepidoptera, Pyralidae). Agronomie 4: 183-187.

Brindley, T. A. \& F. F. Dicke. 1963. Significant developments in European corn borer research. Annu. Rev. Entomol. 8: 155-176.

Buechi, R., E. Preisner \& R. Brunetti. 1982, Das sympatrische vorkommen von zwei pheromonstämmen des maisezünslers, Ostrinia nubilalis $\mathrm{Hbn}$. in der südschweiz. Mitt. Schweiz. Entomol. Ges. 55: 3353.

Cardé, R. T., W. L. Roelofs, R. G. Harrison, A. T. Vawter, P. F. Brussard, A. Mutumera \& E. Munroe. 1978. European corn borer: pheromone polymorphism or sibling species? Science 199: 555-556.

Cianchi, R., S. Maini \& L. Bullini. 1980. Genetic distance between pheromone strains of the European corn borer, Ostrinia nubilalis: different contribution of variable substrate, regulatory and non-regulatory enzymes. Heredity 45:383-388.

Eckenrode, C. J. \& D. R. Webb. 1989. Establishment of various European corn borer (Lepidoptera: Pyralidae) races on selected cultivars of snap beans. J. Econ. Entomol. 82: 1168-1173.

Eekenrode, C. J., P. S. Robbins \& J. T. Andaloro. 1983. Variations in flight patterns of European corn borer (Lepidoptera: Pyralidae) in New York. Environ. Entomol. 12: 393-396.

Glover, T. J., N. Perez \& W. L. Roelofs. 1989. Comparative analysis of sex pheromone-response antagonists in three races of European corn borer. J. Chem. Ecol. 15: 863-873.

Glover, T. J., X.-H. Tang \& W. L. Roelofs. 1987. Sex pheromone blend discrimination by male moths from $\mathrm{E}$ and $\mathrm{Z}$ strains of European corn borer. J. Chem. Ecol. 13: 143-151.

Glover, T. J., M. G. Campbell, P. S. Robbins \& W. L. Roelofs. 1990. Sex-linked control of sex pheromone behavioral responses in European corn borer moths confirmed with TPI marker gene. Arch. Insect Biochem. \& Physiol. 15: 67-77.

Harrison, R. G. \& A. T. Vawter. 1977. Allozyme differentiation between pheromone strains of the European corn borer, Ostrinia nubilalis. Ann. Ent. Soc. Am. 70: 717-720.

Klun, J. A. 1968. Isolation of a sex pheromone of the European corn borer. J. Econ. Entomol. 6: 484-487.
Klun, J. A. \& Cooperators. 1975. Insect sex pheromones: intraspecific pheromonal variability of Ostrinia nubilalis in North America and Europe. Environ. Entomol. 4: 891-894.

Klun, J. A. \& S. Maini. 1979. Genetic basis of an insect chemical communication system: the European corn borer. Environ. Entomol. 8: 423-426.

Klun, J. A. \& J. F. Robinson. 1971. European corn borer: sex attractant and sex attraction inhibitors. Ann. Entomol. Soc. Am. 64: 1083-1086.

Klun, J. A., D. L. Chapman, K. C. Mattes, P. W. Wojtkowski, M. Beroza \& P. E. Sonnet. 1973. Insect sex pheromone: minor amount of the opposite geometrical isomer critical to attraction. Science 181 : $66 \mathrm{l}-663$.

Kochansky, J., R. T. Cardé, J. Liebherr \& W. L. Roelofs. 1975. Sex pheromone of the European corn borer, Ostrinia nubilalis (Lepidoptera: Pyralidae), in New York. J. Chem. Ecol. 1: 225-231.

Kuhr, R. J. \& A. C. Davis. 1975. Toxicity and metabolism of European corn borer. Pestic. Biochem. \& Physiol. 5: 330-337.

Li, C. C. 1976. First course in population genetics. Boxwood, Pacific Grove, Calif.

Liebherr, J. \& W. Roelofs. 1975. Laboratory hybridization and mating period studies using two pheromone strains of Ostrinia nubilalis. Ann. Entomol. Soc. Am. 68: 305-309.

Löfstedt, C., B. S. Hansson, W. L. Roelofs \& B. 0. Bengtsson. 1989. No linkage between genes controlling female pheromone production and male pheromone response in European corn borer, Ostrinia nubilalis Hübner (Lepidoptera: Pyralidae). Genetics 123: 553-556.

McLeod, D.G.R., C. Ritchot \& T. Nagai. 1979. Occurrence of two generation strain of the European corn borer, Ostrinia nubilalis (Lepidoptera: Pyralidae), in Quebec. Can. Entomol. 111: 233-236.

Roelofs, W. L., J.-W. Du, X.-H. Tang, P. S. Robbins \& C. J. Eckenrode. 1985. Three European corn borer populations in New York based on sex pheromones and voltinism. J. Chem. Ecol. 11: 829-836.

Roelofs, W., T. Glover, X.-H. Tang, I. Sreng, P. Robbins, C. Eckenrode, C. Löfstedt, B. Hansson \& B. Bengtsson. 1987. Sex pheromone production and perception in European corn borer moths is determined by both autosomal and sex-linked genes. Proc. Natl. Acad. Sci. U.S.A. 84: 7585-7589.

Smith, H. E. 1920. Broomcorn the probable host in which Pyrausta nubilalis Hübn. reached America. J. Econ. Entomol. 13: 425-430.

Snedecor, G. W. \& W. G. Cochran. 1969. Statistical methods, 6th ed. Iowa State University Press, Ames.

Straub, R. W., R. W. Weires, Jr., \& C. J. Eckenrode. 1986. Damage to apple cultivars by races of $\mathrm{Eu}$ ropean corn borer (Lepidoptera: Pyralidae). J. Econ. Entomol. 79: 359-363.

Vinal, S. C. 1917. The European corn borer, Pyrausta nubilalis Hübner, a recently established pest in Massachusetts, pp. 147-152. In Mass. Agric. Exp. Stn. Bull. 178.

Webb, D. R., C. J. Eckenrode \& M. H. Dickson. 1987. Variation among green and wax beans in survival of larvae of a bivoltine- $E$ race of European corn borer (Lepidoptera: Pyralidae). J. Econ. Entomol. 80: 521524.

Received for publication 30 November 1990; accepted 23 April 1991. 